\title{
The Use of Long-Run Restrictions for the Identification of Technology Shocks
}

\author{
Neville R. Francis, Michael T. Owyang, and Athena T. Theodorou
}

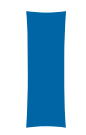
n many economic models, business cycles are driven by some combination of monetary, fiscal, and technological innovations, where "technology" is often thought of as the unexplainable component of the business cycle that is manifested as a change in the overall productive capacity of the economy. Recently, a growing empirical literature has undertaken the challenge of defining technology shocks and their effects on the economy in structural statistical models.

In this paper, we survey the recent literature on long-run identified technology shocks. We present the results of a bivariate vector autoregression (VAR) with labor productivity and labor hours as a benchmark for the recent results found for technology shocks. We then propose an alternative approach for identifying and studying the effects of technology shocks.

We propose a reverse approach to that used in the structural VAR literature, the motivation of which is to provide a robustness check of the recent results from the existing literature. Our new methodology entails four basic steps. We first estimate the reduced form VAR, saving the coefficient and the error variance-covariance matrices. Given the estimated reduced-form coefficient and covariance matrices, the second step is to constrain the impulse response for labor productivity. Specifically, we restrict the sign of the impulse response for productivity such that technology shocks have long-lasting positive effects on productivity. The third step is to collect all the shocks that can generate this long-horizon response of productivity-we call these disturbances potential technology shocks. The final step is to examine the response of labor hours to these shocks. Contrary to standard real business cycle (RBC) theory, recent studies in this literature have found that labor hours respond negatively to a positive technology shock. We test the robustness of this result.

Neville R. Francis is an assistant professor of economics at Lehigh University; Michael T. Owyang is an economist and Athena T. Theodorou is a research associate at the Federal Reserve Bank of St. Louis. The authors thank Valerie Ramey and Tara Sinclair for valuable comments. Kristie Engemann and Mark L. Opitz provided research assistance.

(C) 2003, The Federal Reserve Bank of St. Louis.
The remainder of the paper is organized as follows: We define the properties of the VAR-based technology shock and review the current empirical findings in the second section. In the third section, we examine a standard application of long-run restrictions used to identify technology shocks and present our (bivariate) benchmark results from this exercise. In the fourth section, we employ an alternative form of a long-run restriction that is adapted from the agnostic algorithm originally proposed by Uhlig (1999).

\section{EMPIRICAL TECHNOLOGY SHOCKS: A SURVEY}

The traditional view in macroeconomics was that economic fluctuations arose from transitory shocks, e.g., temporary shocks to monetary and fiscal policy. Secular trends were believed not to contribute to quarter-to-quarter or even year-to-year fluctuations in macroeconomic data. In a very influential paper, King et al. (1991) empirically examined the effects of shifts in stochastic trends common to several macroeconomic series. They presented an economic model with a single common stochastic trend, interpreted as a permanent shock to productivity, that altered the steady state of the model economy. This stochastic trend, the unit root in productivity, is now widely referred to as a "technology shock"; currently, the challenge for macroeconomists is how to more accurately identify this measure of technology shocks.

The growth accounting approach proposed by Solow (1957) has been widely used to identify technology shocks. Under the assumption of competitive markets and constant returns to scale in production, total factor productivity (or the Solow residual) is that part of output that is left unexplained after accounting for the contributions of capital and labor. A typical growth accounting equation would be of the form:

$$
\log \left(Y_{t}\right)=\gamma \log \left(L_{t}\right)+(1-\gamma) \log \left(K_{t}\right)+\log \left(A_{t}\right),
$$

where $Y_{t}$ is period-t output; $K_{t}$ and $L_{t}$ are period- $t$ capital and labor, respectively; $\gamma$ is the labor share of output; and $A_{t}$ is the so-called Solow residual. 
Innovations to the Solow residual were thought of as shocks to technology. ${ }^{1}$ However, there are three potential shortcomings with the use of the Solow residual as a proxy for technology shocks. First, growth accounting does not incorporate either workers' effort or capital utilization. Thus, embedded in the residual $A_{t}$ are these confounding measures that have nothing to do with technology shocks. Second, the probability of technological regress using the Solow residual is of the order of 40 percent, which is implausible to some economists. It is not apparent that the structural VAR (SVAR) method overcomes this criticism, implying that it is nearly equally likely to have technological regress as progress. Third, the measure failed what are now referred to as the Hall (1988) and Evans (1992) tests. These studies found that the Solow residual is correlated with other exogenous shocks-such as shocks to money, interest rates, and government spending - that are not related to technology. ${ }^{2}$

These shortcomings led economists either to seek to improve upon the Solow residual or search for an alternative measure of technology shocks. Basu, Fernald, and Kimball (1998) sought to improve upon the Solow residual by incorporating unobserved factor inputs into their estimations. They followed Hall (1990) and regressed the growth rate of output on the growth rate of inputs at a disaggregated level with proxies for capacity utilization. Technological change is then defined as an appropriately weighted sum of the resulting residuals. They found that technological improvements contradict RBC theory predictions about the (technologydriven) co-movement of labor hours and productivity across the business cycle; specifically, hours fall, at least in the short run, when hit with a productivityimproving technology shock.

The search for an alternative measure of technology shocks has proceeded along two lines. The first line of research concerns the assumption(s) used to identify technology shocks. The second line involves the choice of data used to identify technology shocks and asks: Are technology shocks either (i) a manifestation of the unexplained component

\footnotetext{
1 This view is not the consensus of the growth accounting literature For example, Denison (1979) views productivity as a measure of society's ability to increase standards of living.

2 King and Rebelo (1999) provide a comprehensive survey of the RBC literature. In particular they highlight the features of the RBC model, e.g., indivisible labor and capital utilization, that generate businesscycle-like second moments while correcting for the failures of the Solow residual.
}

of labor productivity or output or (ii) the culmination of research and development?

Proceeding along the first line of research, Gali (1999) attempted to disentangle technology and nontechnology shocks by analyzing labor productivity and hours of employment. He estimated a SVAR with the key identifying assumption that technology shocks alone can produce long-run effects on labor productivity. ${ }^{3}$ Gali estimated a bivariate model of productivity and hours. ${ }^{4} \mathrm{He}$ found that hours fell in response to a shock that permanently raised labor productivity (the technology shock). Gali thus concluded that technology shocks were not the driving force behind cyclical fluctuations and that his "nontechnology" shocks better explained the short-run movements in aggregate economic data. Kiley (1998) followed Gali and applied a similar methodology to 17 two-digit manufacturing industries. He found that, for a majority of these industries, technology shocks identified by these SVARs produced the same negative hours response as found for the aggregate data.

Francis and Ramey (2002) used Gali as a starting point in their recent analysis of technology shocks. Using the SVAR approach, they reexamined Gali's work by first testing whether the shocks identified in this framework can be plausibly interpreted as technology shocks. They first derived additional long-run restrictions and used them as overidentifying tests. For example, they estimated a model of real wages and hours with the assumption that only technology shocks can have permanent effects on real wages. If this assumption is true, then real wages and productivity should share a common trend, an assumption not rejected by the data. ${ }^{5}$ Next, they augmented Gali's basic model with data on real wages, investment, and consumption and determined whether the impulse responses for these variables accorded with theory. Finally, they tested whether their technology shocks were Grangercaused by exogenous events unrelated to technology as per Hall (1988) and Evans (1992). Their measure of technology survived the scrutiny of all three tests.

\footnotetext{
3 In a bivariate framework, the employed identification is equivalent to a Wold causal chain structure in the long run.

4 Gali (1999) also estimates a five-variable model that includes money, inflation, and interest rates. Results from this model are consistent with the bivariate framework.

5 The first-order condition states that workers are each paid their marginal product. Therefore, it stands to reason that the same assumption for the effect of technology shocks on labor productivity must also hold for technology shocks on real wages.
} 
However, they still found that labor hours responded negatively on impact to a technology shock. ${ }^{6}$

Shea (1999) proceeded along the second line of research. He used data on both patents and research and development to identify technology shocks and found that hours fell in response to a technology shock. However, unlike the above studies, the decline in hours is a long-run response-that is, hours rise in the short run but then eventually fall.

In sum, using different methodologies to identify technology shocks, these recent lines of research have produced similar results. Further, the identified technology shock is unable to explain a substantial proportion of the variation in hours across the business cycle. Our contribution will be to add a fourth methodology that provides a robustness check of the SVAR results.

\section{IMPLEMENTING LONG-RUN RESTRICTIONS}

In this section, we present a bivariate long-run restricted SVAR model of productivity and hours as a benchmark to the technology literature. Essentially, this section reproduces the bivariate results described in Gali (1999) and Francis and Ramey (2002).

\section{Data}

The data are quarterly and cover the period 1948:Q1 to 2000:Q4. The labor productivity series is from the Bureau of Labor Statistics (BLS) "Index of output per hour, business," while the labor hours series is from the BLS "Index of hours in business." We tested and failed to reject unit roots for both labor productivity and hours; therefore, in our benchmark VAR specification, we enter these series in first differences. Productivity and labor are also not cointegrated. We use four lags of the dependent variables in each equation of the VAR. The lag length was chosen by means of the Schwarz or Bayesian information criterion (BIC).

\section{Econometric Framework}

The recent methodology of choice in the technology shock literature is the SVAR, a standard reduced-form VAR with additional restrictions that

6 Christiano, Eichenbaum, and Vigfusson (2003) and Uhlig (2002) challenge the results of the aforementioned literature. They claim that hours entered in levels would overturn the negative short-run hours response when a technology shock hits the economy. However, Francis and Ramey (2003), in another unpublished manuscript, show that hours, properly detrended, experiences a decline on impact of a technology shock. are drawn from theory to separate and identify the components of the residuals. These restrictions can be short run (often comprising short-run restrictions or the impact effects of shocks) or long run. A discussion of long-run restrictions follows.

Consider the following $k$-lag VAR:

$$
\Phi(L) Y_{t}=\varepsilon_{t},
$$

where

$$
\begin{aligned}
& Y_{t}=\left[\begin{array}{l}
\Delta x_{t} \\
\Delta n_{t}
\end{array}\right], \\
& \varepsilon_{t}=\left[\begin{array}{c}
\varepsilon_{t}^{x} \\
\varepsilon_{t}^{n}
\end{array}\right],
\end{aligned}
$$

and $\Phi(L)$ is a $k$ th-order matrix polynomial in the lag operator. The VAR can be rewritten in its moving average (MA) representation:

$$
Y_{t}=C(L) \varepsilon_{t},
$$

where $C(L)$ is a (infinite) polynomial matrix in the lag operator $\Phi(L)=C(L)^{-1}$. The series $x_{t}$ denotes the $\log$ of labor productivity, and $n_{t}$ denotes the log of labor hours. We label $\varepsilon_{t}^{x}$ the technology shock and $\varepsilon_{t}^{n}$ the non-technology shock, and we make the usual assumption that these shocks are orthogonal and serially uncorrelated.

For ease of exposition, it is useful to rewrite (1) as

$$
Y_{t}=\left[\begin{array}{ll}
C_{11}(L) & C_{12}(L) \\
C_{21}(L) & C_{22}(L)
\end{array}\right]\left[\begin{array}{c}
\varepsilon_{t}^{x} \\
\varepsilon_{t}^{n}
\end{array}\right] .
$$

We impose long-run restrictions to identify the technology shock, $\varepsilon_{t}^{x}$. Each of the matrices in (2) is a polynomial in the lag operator. To achieve exact identification, we restrict the non-technology shock's long-run impact on productivity to be zero. This assumption identifying the technology shock implies that $C_{12}(1)=0$, which restricts the unit root in productivity to originate solely from the technology shock. ${ }^{7}$ The identifying restrictions do not restrict the effect the technology shock can have on hours at either the long or short horizon. ${ }^{8}$

We estimate the model using the method pro-

\footnotetext{
7 In principle, the model presented above could be augmented to measure the effects of shocks on other variables (see Gali, 1999, and Francis and Ramey, 2002). The identification scheme here assumes that any other shock, regardless of the size of the system, has no long-run effect on labor productivity.

8 It can be shown that the identification scheme explained in this section is equivalent to a Wold causal chain on the steady-state structure of the model (see Rasche, 2001).
} 


\section{Impulse Responses to a Technology Shock (95\% Bootstrapped Standard Error Bands)}
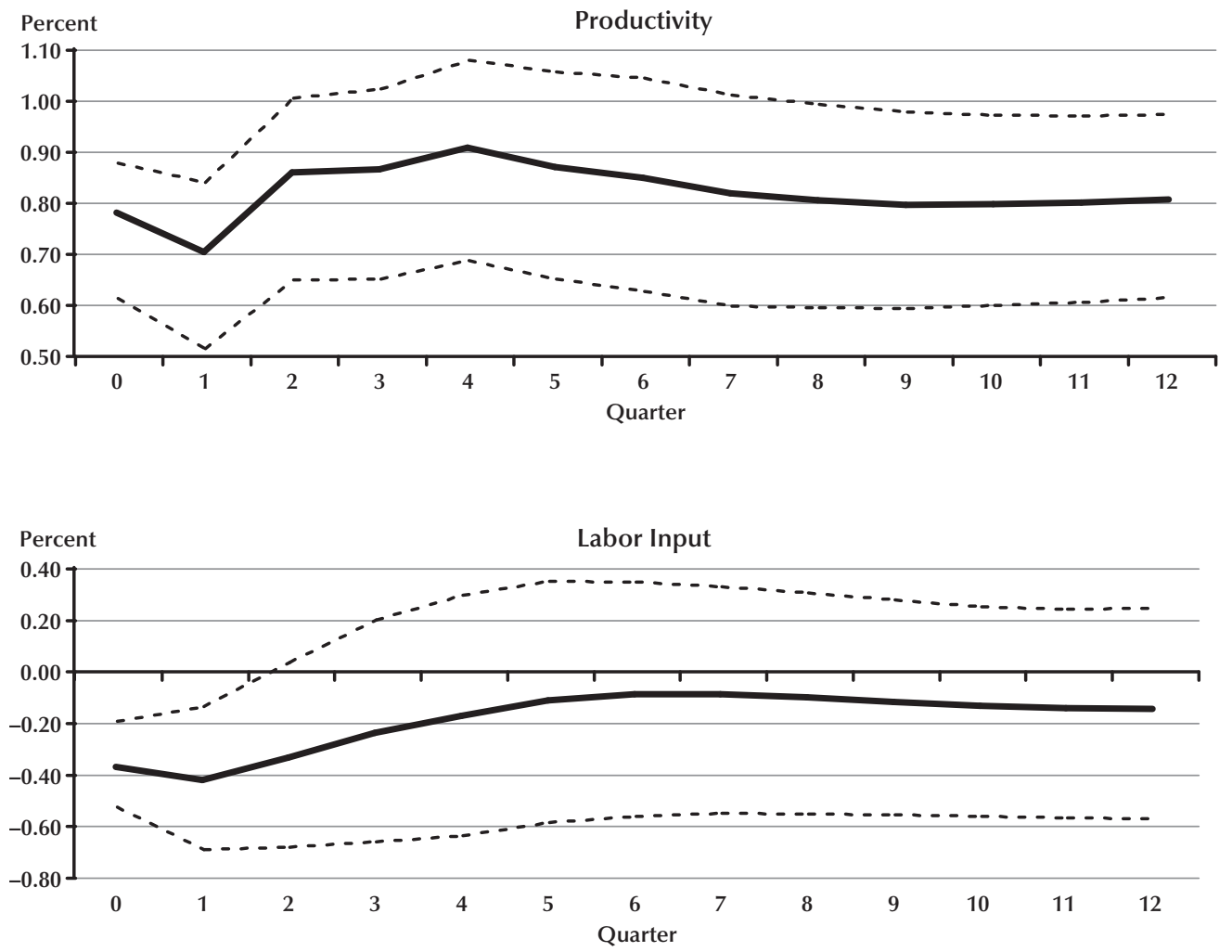

posed by Shapiro and Watson (1988). By using this method we can estimate the equations in the VAR one at a time. The productivity equation is as follows:

$$
\Delta x_{t}=\sum_{j=1}^{p} \alpha_{x x, j} \Delta x_{t-j}+\sum_{j=0}^{p-1} \beta_{x n, j} \Delta^{2} n_{t-j}+\varepsilon_{t}^{x},
$$

where $\Delta^{2}$ is the square of the difference operator. Imposing the long-run restriction is equivalent to restricting the hours variable to enter the productivity equation (3) in double differences. ${ }^{9}$ Because the current value of $\Delta^{2} n_{t}$ will be correlated with $\varepsilon_{t}^{x}$, we estimate this equation using instrumental variables. We use lags 1 through $p$ of $\Delta x_{t}$ and $\Delta n_{t}$ as instruments. The hours equation is then estimated as follows:

9 Labor hours enters in double differences because we assume that labor hours has a unit root. If the labor hours series were stationary, then, to impose long-run restrictions, we would enter hours into the productivity equation in first differences.
(4) $\Delta n_{t}=\sum_{j=1}^{p} \alpha_{n x, j} \Delta x_{t-j}+\sum_{j=1}^{p} \alpha_{n n, j} \Delta n_{t-j}+\rho_{n, x} \varepsilon_{t}^{x}+\varepsilon_{t}^{n}$.

Technology, $\varepsilon_{t}^{x}$, enters into the hours equation (4) in order to achieve orthogonality between the technology and non-technology shocks. We estimate the hours equation using ordinary least squares, since there is no contemporaneous independent variable that would be correlated with the residual $\varepsilon_{t}^{n}$. The Shapiro-Watson methodology, applied to the same data, produces results identical to the matrix method used by Gali. ${ }^{10}$ We present results from an illustrative two-variable system in the next subsection.

\section{Benchmark Results}

Figure 1 presents the impulse responses from a shock to technology in the bivariate model of labor

\footnotetext{
10 The interested reader is directed to Appendix A for a detailed derivation of the long-run restriction methodology. There, we demonstrate the equivalence between the matrix method and the Shapiro-Watson method of long-run identification.
} 


\section{Figure 2}

\section{Impulse Responses to a Non-Technology Shock (95\% Bootstrapped Standard Error Bands)}
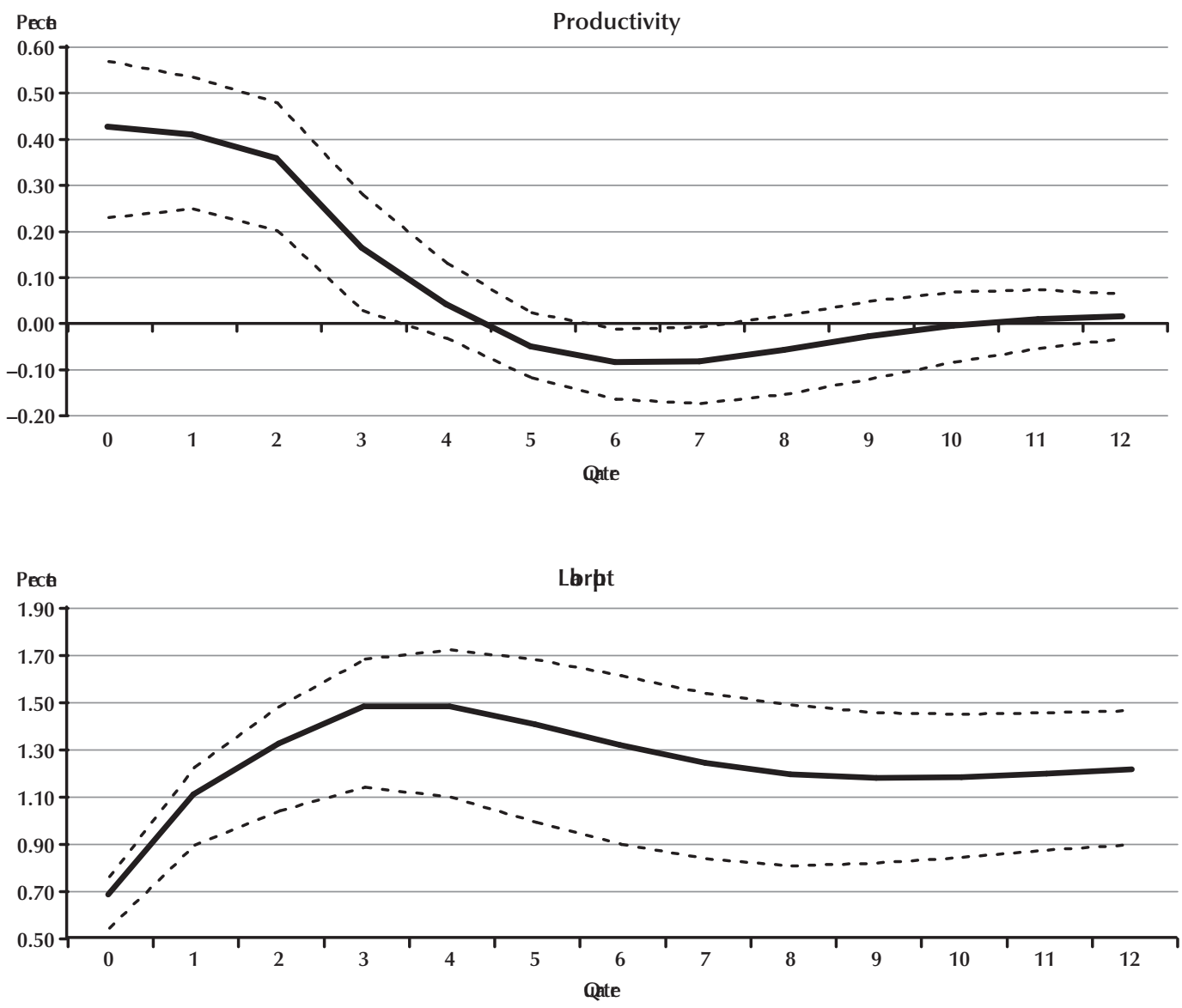

productivity and hours. ${ }^{11}$ Labor productivity immediately rises by 0.8 percent, displays a hump-shaped pattern, and eventually settles to a new steady state approximately 0.8 percentage points above its preshock level. This persistent rise in productivity is at the heart of the identification, as only the technology shock can have this permanent positive effect.

The hours response is somewhat curious. On impact, labor hours experience a statistically significant decline in response to the technology shock; moreover, the point estimate for the response remains negative for the entire response period. However, according to the 95 percent bootstrapped confidence bands, the decline in labor hours is sta-

\footnotetext{
11 Note that this is identical to Figure 1a in Francis and Ramey (2002).
}

tistically significant for only two quarters; thereafter, it is insignificantly different from zero.

The responses of labor productivity and hours to a non-technology shock - the shock that, according to Gali (1999), coincides with cyclical fluctuations-are shown in Figure 2.12 Labor productivity gradually rises for about one year, but eventually the effect of the non-technology shock on productivity disappears over time. On the other hand, the non-technology shock has a permanent impact on hours worked. Following the shock, hours worked increases for about one year, displaying a humpshaped pattern, and eventually reaches a new steady state higher than its pre-shock level.

\footnotetext{
12 We refrain from attributing any structural interpretation to the nontechnology shock. This shock can be thought of as a combination of a number of shocks that remain unidentified within our system.
} 


\section{IMPULSE RESPONSE RESTRICTIONS}

In this section, we demonstrate how long-run restrictions can be implemented in a framework that leaves the structural parameters of the VAR unrestricted but, instead, imposes sign restrictions on the resulting impulse responses (see Uhlig, 1999). ${ }^{13}$ We can, therefore, estimate the model without imposing the exact restrictions on the estimated parameters, as in the long-run identification schemes of Blanchard and Quah (1989) and Shapiro and Watson (1988). We search for shocks that produce impulse responses consistent with what we believe technology should produce, i.e., a long-run positive response to labor productivity. Our goal is to determine the robustness of the results found in the preceding section by determining the percentage of long-run effective shocks that produce an hours/ productivity negative co-movement.

An additional advantage to this approach, which we leave to be exploited by further research, is that hypothetical responses can be posed. The resulting shocks required to induce those responses can be computed and used to perform counterfactual experiments. In this sense, we can work backward to test the validity of our assumptions about the effects of the shocks by performing, say, exogeneity tests. ${ }^{14}$

\section{Framework}

Here, we outline the methodology that incorporates restrictions on the signs of the impulse responses to identify the model. What we are doing, in essence, is defining how a type of shock should effect the economy and determining which shocks might generate those results. While, to the casual reader, this identification might seem to be constructed backward, it has theoretical foundations that are detailed in Appendix B.

Formally, the reaction to the reduced-form shock ( $e_{t}$ from Appendix B) cannot be interpreted in a structural context. However, it can be shown that the structural shock $\varepsilon_{t}$ is related to the reducedform shock by means of the contemporaneous impact matrix, $A_{0}$ :

$$
e_{t}=A_{0}^{-1} \varepsilon_{t}
$$

\footnotetext{
13 Other ex post restrictions could also be employed. Examples of these include restricting the forecast error variances (Faust, 1998) or the cross-correlation (Canova and De Nicolo, 2002).

${ }^{14}$ An example of this line of research can be found in Francis and Owyang (2003)
}

where $A_{0}^{-1} A_{0}^{-1^{\prime}}=\Sigma$. Thus, the $j$ th column of the matrix $A_{0}^{-1}$ can be interpreted as the contemporaneous effect of the $j$ th fundamental shock (which we will call an impulse vector). However, this decomposition is not unique; for any orthonormal matrix $Q$, $A_{0}^{-1} Q Q^{\prime} A_{0}^{-1^{\prime}}=\Sigma$ is also a permissible decomposition. In the previous section, we distinguished between acceptable rotations by imposing restrictions on the form of the rotation matrix $Q$.

The identification technique we employ in this section involves sampling from the distributions for both the coefficient and covariance matrices that are estimated from the model's reduced form. We draw a candidate impulse vector and compute the impulse response; each impulse vector that generates an impulse response consistent with a predetermined set of sign restrictions is saved. ${ }^{15}$ Iteration of this process generates a distribution for the impulse vectors we will call technology shocks.

While the methodology utilized in the previous section uniquely identified a (estimated) reducedform shock, the technique in this section estimates a distribution for this shock. Exact identification using this technique requires a large number of restrictions, since the constraints on the impulse responses may not bind at all horizons. Thus, instead of imposing, for example, an explicit causal ordering, we are able to define the technology shock based on its ex post impulse response for certain variables. We concentrate on identification of the technology shock. In principle, other shocks that are effectorthogonal, i.e., have sets of mutually exclusive restrictions, could also be identified.

A number of recent papers have employed this algorithm to impose sign restrictions on impulse responses. Uhlig (1999, 2001) and Owyang (2002) restrict the responses of both inflation and interest rates to identify a monetary shock. Mountford and Uhlig (2002) impose restrictions on revenues, expenditures, and deficits to identify fiscal shocks. However, these applications of the algorithm have centered primarily on the short-run responses to shocks. Here, we can adapt the algorithm to test for restrictions at long horizons. In this application, we constrain the long-run response of labor productivity to a technology shock to be positive. ${ }^{16}$

\footnotetext{
${ }^{15}$ Mathematical details for the estimation and identification can be found in Appendix C. For an explicit discussion of the relationship between the impulse vector and the identified structural shock, see Uhlig (1999).

${ }^{16}$ In addition to long-horizon restrictions on the productivity response, we also impose impact restrictions. We assume that a positive technology shock raises productivity on impact.
} 


\section{Figure 3}

Distributions of the Impact Effects on the Two-System Variables
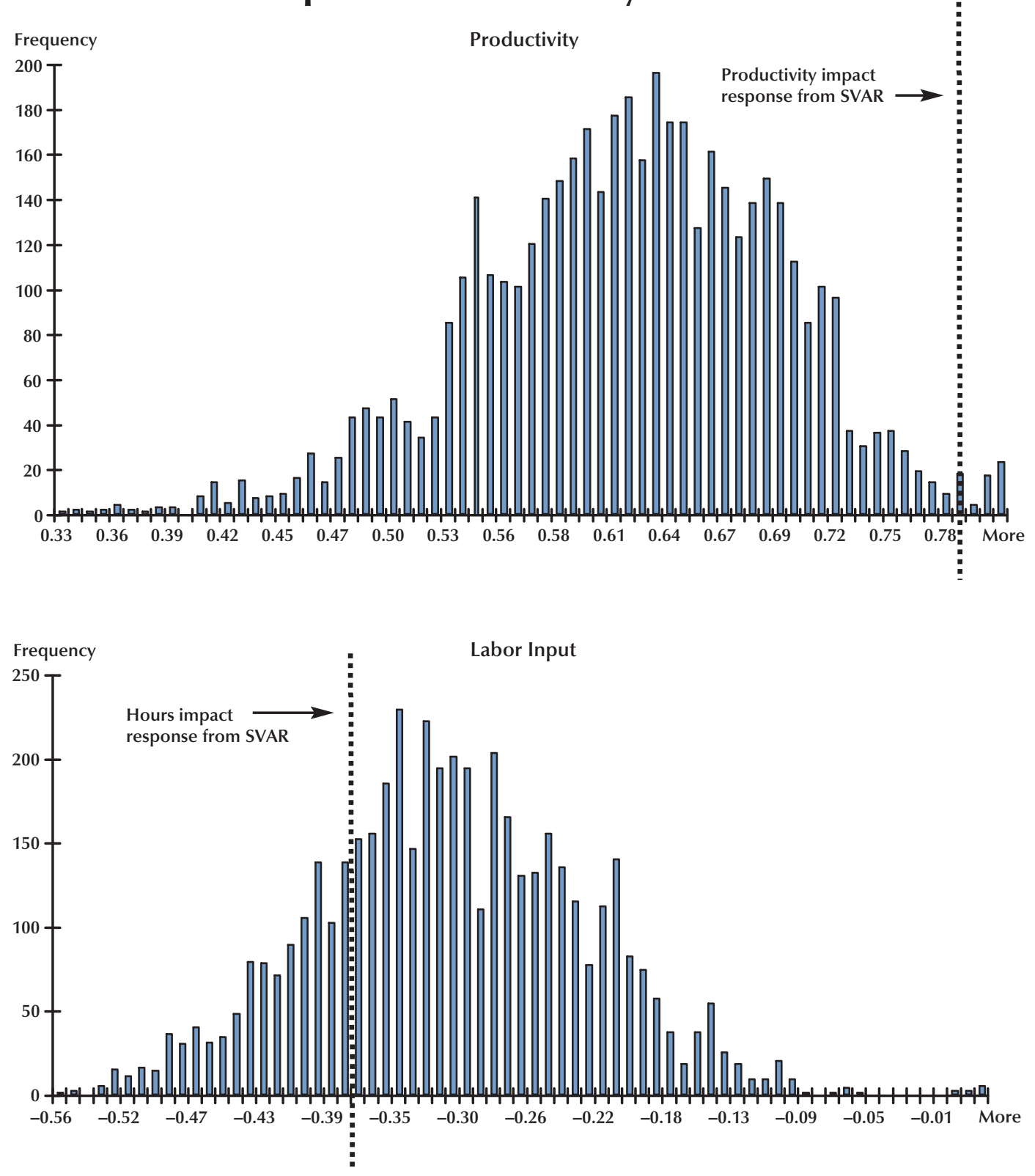

\section{Empirical Results}

The system that we estimate is a VAR with prior distributions on the parameters that we describe in Appendix C. We make 1000 draws from the posterior distributions generated by estimating the VAR. For each draw from the parameter space, we draw 1000 candidate shocks. ${ }^{17}$

${ }^{17}$ We forgo identification of the hours shock in this section. Identification
The distributions of the impact effects on the two-system variables are shown in Figure 3. We include the point estimates of the impact effects for the exactly identified shock from the previous section. Labor productivity's impact response from the SVAR lies to the right of the mean of the impact

of this shock can be achieved either through independent draws or by utilizing an orthogonality assumption to decompose the system residuals. 


\section{Figure 4}

\section{Impulse Responses for Sign-Restriction Algorithm for Labor Input in Differences (60\% Coverage Interval Shown)}
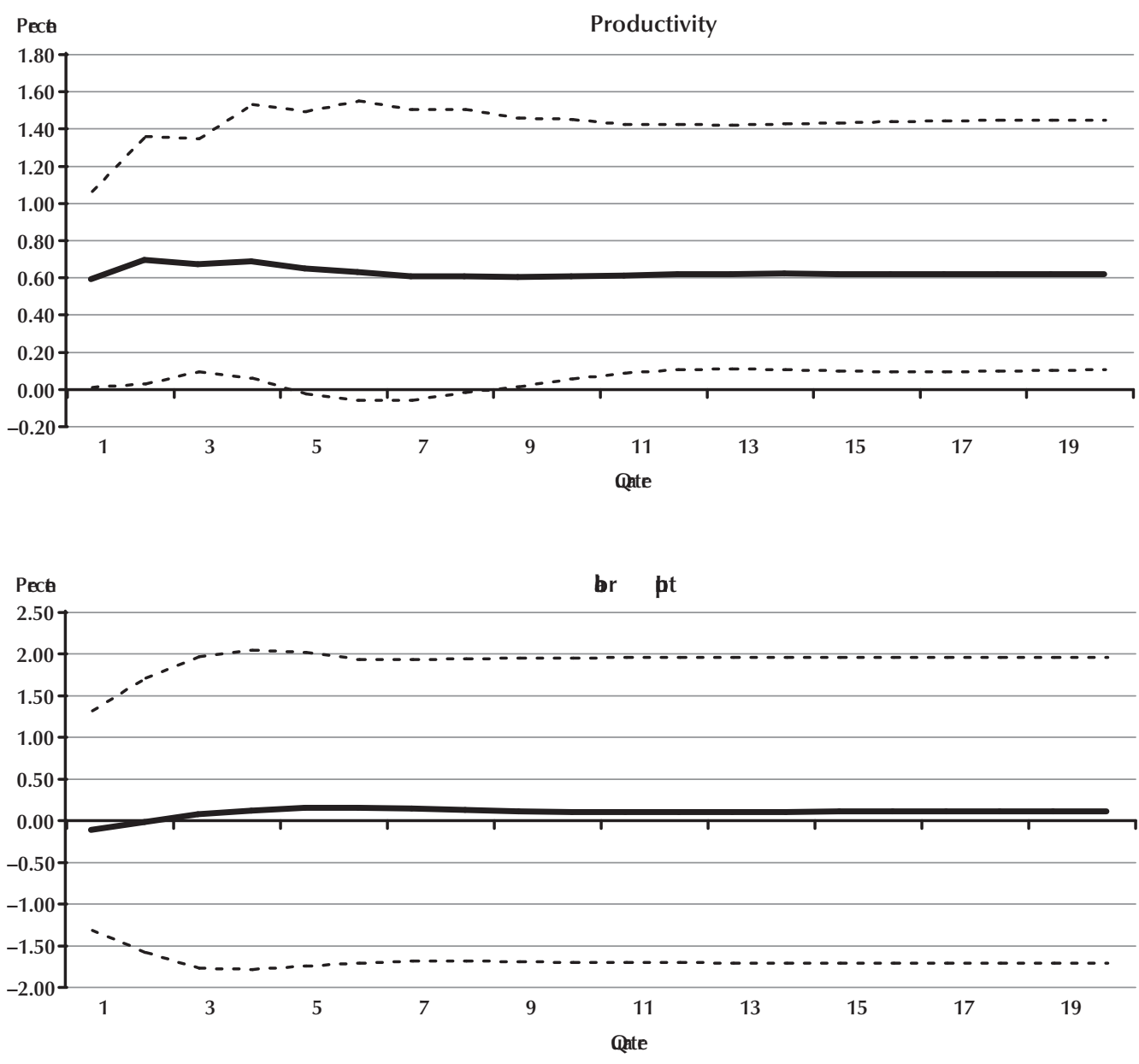

distribution from the sign-restriction algorithm. That is, the initial productivity response from the SVAR is greater than the mean impact response obtained from the sign-restriction algorithm. However, the opposite is true for the hours response. That is, the hours response from the SVAR lies to the left of the mean of the impact distribution from the sign-restriction approach. Therefore, the signrestriction algorithm produces initial hours responses that are invariably less negative (i.e., closer to zero) than the impact response obtained from the SVAR with long-run restrictions. In this sense the signrestriction approach is less restrictive than the SVAR approach but nevertheless produces an initial hours response that is negative on average. ${ }^{18}$
The resulting mean impact effects of the identified technology shock are

$$
\hat{a}=\left[\begin{array}{r}
0.62 \\
-0.31
\end{array}\right],
$$

(0.62 for labor productivity and -0.31 for labor hours), and the associated impulse responses are

18 The same is true when the sign-restriction algorithm has hours entering the VAR in levels. This means that the SVAR with hours in levels does not impose enough restrictions to identify technology shocks. In these SVARs, non-technology shocks have long-lasting effects on productivity, contrary to the initial identifying assumption. Our algorithm with hours in levels imposes enough ex post restrictions to circumvent such problems and thus produces negative labor hours results just like its first-differenced counterpart. See Francis and Ramey (2003) for further exposition. 


\section{Figure 5}

\section{Impulse Responses for Sign-Restriction Algorithm for Labor Input in Differences with Long-Run Neutrality of Technology on Hours (60\% Coverage Interval Shown)}
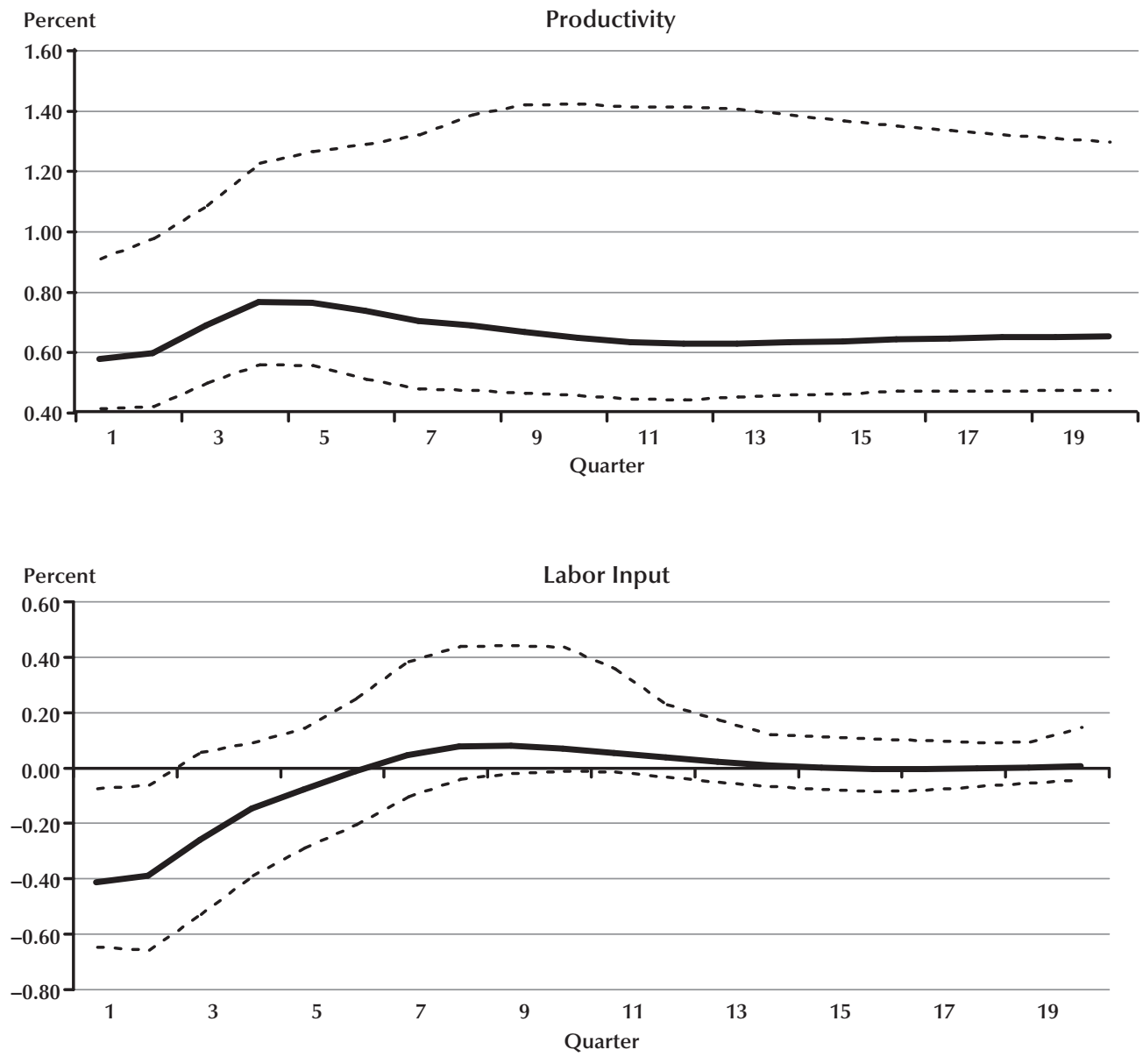

illustrated in Figure $4 .{ }^{19}$ For the long-horizon signrestriction algorithm, we compute the responses out to 40 quarters. Consistent with the findings above, this estimation presupposes that labor hours possesses a unit root and is entered in differences. The productivity response to a technology shock is positive on impact and converges to a steady-state value of 0.6 percent approximately eight periods after the initial shock. The algorithm imposes a rise in labor productivity in the tenth year. ${ }^{20}$ However,

\footnotetext{
${ }^{19}$ Figure 4 shows the mean response of the technology shock over the saved draws. In addition, we provide a coverage interval that shows the interior 60 percent of the distribution of effects. We do not provide standard error bands since the distributions for the impulse responses may be non-normal.

${ }^{20}$ In other words, we calculate the impulse responses for 40 periods
}

we note that the response to a technology shock for the majority of prior periods turns out to also be positive.

Next, note that the average labor hours response is negative on impact. In fact, in approximately 95 percent of the accepted draws, the candidate technology shock produces a negative response of hours on impact. However, on average, the decrease in hours is not permanent. Based on our findings using this impulse response-restricted algorithm, we cannot reject the hypothesis that a technology shock causes labor hours to fall on impact. This conclusion stems from our ability to draw a variety of candidate

and impose that the productivity response from the 37 th to the 40 th periods be positive. 
shocks, which produce both long-run productivity responses and negative hours responses. ${ }^{21}$

Finally, note that the coverage intervals in Figure 4 are relatively large compared with the error bands associated with the SVAR in the preceding section. Recall that the technology shock produced by the impulse response-restricted algorithm is not exactly identified - that is, the algorithm identifies only a distribution for the candidate shocks. Exact identification requires further restrictions, and each additional (binding) restriction contributes to a narrowing in the coverage intervals. As an example of this, consider Figure 5. Here, we have identified the technology shock with the additional restriction that imposes long-run neutrality of technology on hours, i.e., the impulse response of hours to a technology shock is negligible at long horizons. In particular, notice that the coverage interval for the hours response is much narrower and that, in this case, a positive hours response on impact is even less likely to occur.

\section{CONCLUSION}

Economists have long assumed that one of the primary components of the business cycle is shocks to technology that produce long-run changes in labor productivity. In this article, we surveyed some recent papers that attempted to identify such shocks. We especially focused on papers using the SVAR approach, with its accompanying long-run restrictions, to identify technology shocks.

Recent results using the SVAR approach to identify technology shocks have shown that they induce a negative impact response of labor hours. Further, using a long-horizon impulse responserestricted system, we generated "technology" by assuming that it is the only shock with a long-horizon impact (say, out to ten years) on labor productivity. Technology shocks generated with this methodology invariably produce the (non-standard) negative labor hours impact result. That is, the probability of having a fall in hours is found to be greater than the probability of having a rise in hours for technology generated in this manner, regardless of whether the VAR is estimated with labor hours in levels or in first differences.

Future research could apply the impulse response-restricted technique in larger macroeconomic models instead of the bivariate model

\footnotetext{
21 We performed a similar analysis using labor hours in levels. We found that the hours response to a positive technology shock is still, on average, negative on impact.
}

employed here. From this we could examine which technology shock, from labor hours in levels or in first differences, produces the more plausible impulses for variables such as consumption, investment, and real wages. Future research should also examine which measure of technology stands up to the scrutiny of the Hall-Evans tests as per Francis and Ramey (2002).

\section{REFERENCES}

Basu, Susantu; Fernald, John and Kimball, Miles. "Are Technology Improvements Contractionary?” International Finance Discussion Papers 1998-625, Board of Governors of the Federal Reserve System, September 1998.

Blanchard, Olivier Jean and Quah, Danny. "The Dynamic Effects of Aggregate Demand and Supply Disturbances." American Economic Review, September 1989, 79(4), pp. 655-73.

Canova, Fabio and De Nicolo, Gianni. "Monetary Disturbances Matter for Business Fluctuations in the G-7." Journal of Monetary Economics, September 2002, 49(6), pp. 1131-59.

Christiano, Lawrence J.; Eichenbaum, Martin and Vigfusson, Robert. "What Happens After a Technology Shock?" NBER Working Paper No. 9819, National Bureau of Economic Research, July 2003.

Denison, Edward F. Accounting for Slower Growth: The United States in the 1970s. Washington, DC: The Brookings Institution, 1979.

Evans, Charles L. "Productivity Shocks and Real Business Cycles.” Journal of Monetary Economics, April 1992, 29(2), pp. 191-208.

Faust, Jon. "The Robustness of Identified VAR Conclusions About Money." Carnegie-Rochester Conference Series on Public Policy, December 1998, 49(0), pp. 207-44.

Francis, Neville R. and Owyang, Michael T. "What Is a Technology Shock? A Bayesian Perspective.” Unpublished manuscript, 2003.

and Ramey, Valerie A. "Is the TechnologyDriven Real Business Cycle Hypothesis Dead? Shocks and Aggregate Fluctuations Revisited." NBER Working Paper No. 8726, National Bureau of Economic Research, January 2002.

and "The Source of Historical 
Economic Fluctuations: An Analysis Using Long-Run Restrictions.” Unpublished manuscript, May 2003.

Gali, Jordi. “Technology, Employment, and the Business Cycle: Do Technology Shocks Explain Aggregate Fluctuations?" American Economic Review, March 1999, 89(1), pp. 249-71.

Hall, Robert E. "The Relation Between Price and Marginal Cost in U.S. Industry." Journal of Political Economy, October 1988, 96(5), pp. 921-47.

"Invariance Properties of Solow's Residual," in Peter Diamond, ed., Growth, Productivity, Unemployment. Cambridge, MA: MIT Press, 1990.

Kiley, Michael T. "Labor Productivity in U.S. Manufacturing: Does Sectoral Comovement Reflect Technology Shocks?" Unpublished manuscript, 1998.

King, Robert G.; Plosser, Charles I.; Stock, James H. and Watson, Mark W. "Stochastic Trends and Economic Fluctuations." American Economic Review, September 1991, 81(4), pp. 819-40.

and Rebelo, Sergio T. "Resuscitating Real Business Cycles," in Handbook of Macroeconomics. Volume 1B. New York: Elsevier Science, North-Holland, 1999, pp. 927 1007.

Mountford, Andrew and Uhlig, Harald. "What Are the Effects of Fiscal Policy Shocks?” Discussion Paper 3338, Centre for Economic Policy Research, April 2002.

Owyang, Michael T. "Modeling Volcker as a Non-Absorbing
State: Agnostic Identification of a Markov-Switching VAR." Working Paper 2002-018A, Federal Reserve Bank of St. Louis, 2002.

Rasche, Robert H. "Identification of Dynamic Economic Models from Reduced Form VECM Structures: An Application of Covariance Restrictions." Working Paper 2000-011B, Federal Reserve Bank of St. Louis, 2001.

Shapiro, Matthew D. and Watson, Mark W. "Sources of Business Cycle Fluctuations," in Stanley Fischer, ed., NBER Macroeconomics Annual 1988, Volume 3.

Cambridge, MA: MIT Press, 1988, pp. 111-48.

Shea, John. "What Do Technology Shocks Do?" in Ben Bernanke and Julio Rotemberg, eds., NBER Macroeconomics Annual 1998. Volume 13. Cambridge, MA: MIT Press, 1999, pp. 275-310.

Solow, Robert M. "Technical Change and the Aggregate Production Function." Review of Economics and Statistics, August 1957, 39, pp. 312-20.

Uhlig, Harald. "What Are the Effects of Monetary Policy on Output? Results from an Agnostic Identification Procedure.” Research Discussion Paper 28, Tilburg University, Center for Economic Research, 1999.

"Did the FED Surprise the Market in 2001? A Case Study for VARs with Sign Restrictions.” Discussion Paper 88, Tilburg University, Center for Economic Research, 2001.

"Do Productivity Shocks Lead to a Decline in Labor?” Unpublished manuscript, 2002. 


\section{Appendix A}

Recall from (1) the MA representation of the VAR, reproduced here for convenience:

$$
Y_{t}=C(L) \varepsilon_{t},
$$

where we have implicitly assumed that $C(L)$ is invertible, $C(L)^{-1}=\Phi(L), \Phi(L)$ is the matrix polynomial in the lag operator, and the roots of $|\Phi(z)|$ are outside the unit circle. From the assumption that only technology can have long-run effects on productivity, $C(1)$ is lower triangular, which implies that $\Phi(1)$ is also lower triangular. ${ }^{22}$

The first equation of $\Phi(L) Y_{t}=\varepsilon_{t}$ then becomes

$$
\text { (A.1.1) } \Delta x_{t}=\sum_{j=1}^{p} \alpha_{x x, j} \Delta x_{t-j}+\sum_{j=0}^{p} \alpha_{x n, j} \Delta n_{t-j}+\varepsilon_{t}^{x} \text {. }
$$

Since $\Phi(1)$ is lower triangular, the long-run multiplier on $\Delta n_{t}$ is identically zero, so the coefficients of its lags sum to zero. (Note, we do not impose any short-run dynamics so the contemporaneous value of $\Delta n_{t}$ appears in the productivity $\left(\Delta x_{t}\right)$ equation.)

Imposing this constraint yields

$$
\Delta x_{t}=\sum_{j=1}^{p} \alpha_{x x, j} \Delta x_{t-j}+\sum_{j=0}^{p-1} \beta_{x n, j} \Delta^{2} n_{t-j}+\varepsilon_{t}^{x} .
$$

The preceding equation is only a matter of algebra. The equivalence of the two methods is shown in the example below for a particular lag length.

Set $p=4 .^{23}$ Then, rewrite (A.1.1) as

\footnotetext{
22 We are essentially imposing that the system is a Wold causal chain structure in the steady state.

${ }^{23}$ We arbitrarily choose four lags, but the results will hold true for any general lag length.
}

(A.1.2)

$$
\begin{aligned}
\Delta x_{t} & =\alpha_{x x, 1} \Delta x_{t-1}+\alpha_{x x, 2} \Delta x_{t-2}+\alpha_{x x, 3} \Delta x_{t-3} \\
& +\alpha_{x x, 4} \Delta x_{t-4}+\alpha_{x n, 0} \Delta n_{t}+\alpha_{x n, 1} \Delta n_{t-1} \\
& +\alpha_{x n, 2} \Delta n_{t-2}+\alpha_{x n, 3} \Delta n_{t-3}+\alpha_{x n, 4} \Delta n_{t-4}+\varepsilon_{t}^{x} .
\end{aligned}
$$

In this case, the long-run restriction $C_{12}{ }^{(1)}=0$ of lower triangularity implies

$$
\alpha_{x n, 0}+\alpha_{x n, 1}+\alpha_{x n, 2}+\alpha_{x n, 3}+\alpha_{x n, 4}=0
$$

Thus, we have

$$
\begin{aligned}
\Delta x_{t} & =\sum_{j=1}^{4} \alpha_{x x, j} \Delta x_{t-j}+\alpha_{x n, 0} \Delta n_{t}+\alpha_{x n, 1} \Delta n_{t-1} \\
& +\alpha_{x n, 2} \Delta n_{t-2}+\alpha_{x n, 3} \Delta n_{t-3}+\alpha_{x n, 4} \Delta n_{t-4} \\
& =\sum_{j=1}^{4} \alpha_{x x, j} \Delta x_{t-j}+\alpha_{x n, 0}\left[\Delta n_{t}-\Delta n_{t-1}\right] \\
& +\left[\alpha_{x n, 0}+\alpha_{x n, 1}\right]\left(\Delta n_{t-1}-\Delta n_{t-2}\right) \\
& +\left[\alpha_{x n, 0}+\alpha_{x n, 1}+\alpha_{x n, 2}\right]\left(\Delta n_{t-2}-\Delta n_{t-3}\right) \\
& +\left[\alpha_{x n, 0}+\alpha_{x n, 1}+\alpha_{x n, 2}+\alpha_{x n, 3}\right]\left(\Delta n_{t-3}-\Delta n_{t-4}\right) \\
& +\left[\alpha_{x n, 0}+\alpha_{x n, 1}+\alpha_{x n, 2}+\alpha_{x n, 3}+\alpha_{x n, 4}\right] \Delta n_{t-4}
\end{aligned}
$$

Restriction (A.1.3) implies that the coefficient on $\Delta n_{t-4}$ is identically zero. Thus, we have

(A.1.4)

$$
\begin{aligned}
\Delta x_{t} & =\sum_{j=1}^{4} \alpha_{x x, j} \Delta x_{t-j}+\alpha_{x n, 0} \Delta^{2} n_{t}+\left(\alpha_{x n, 0}+\alpha_{x n, 1}\right) \Delta^{2} n_{t-1} \\
& +\left(\alpha_{x n, 0}+\alpha_{x n, 1}+\alpha_{x n, 2}\right) \Delta^{2} n_{t-2} \\
& +\left(\alpha_{x n, 0}+\alpha_{x n, 1}+\alpha_{x n, 2}+\alpha_{x n, 3}\right) \Delta^{2} n_{t-3}+\varepsilon_{t}^{x} .
\end{aligned}
$$

We rewrite this as

$$
\text { (A.1. } \left.4^{\prime}\right) \Delta x_{t}=\sum_{j=1}^{4} \alpha_{x x, j} \Delta x_{t-j}+\sum_{j=0}^{3} \beta_{x n, j} \Delta^{2} n_{t-j}+\varepsilon_{t}^{x} \text {, }
$$

where the $\beta$ s are functions of the $\alpha$ s. Note that equation (A.1.4') here is identical to (3).

The hours equation (4) is straightforward. Note that we do not require the contemporaneous value of $\Delta x_{t}$ in the hours equation since $\varepsilon_{t}^{x}$ enters into equation (4) directly. 


\section{Appendix B}

Consider the reduced-form VAR

$$
A(L) Y_{t}=e_{t},
$$

where $A(L)$ is an $(n \times n)$ matrix of lag polynomials and $e_{t} \sim N(0, \Sigma)$. We can rewrite this VAR in its $M A(\infty)$ representation:

$$
Y_{t}=B(L) e_{t},
$$

where $B(L)=A(L)^{-1}$. The model residuals $e_{t}$ have no structural interpretation; the objective of this exercise is to identify the structural shocks $\varepsilon_{t}$ defined in the third section, on implementing longrun restrictions. This can be accomplished by imposing restrictions on either the contemporary impact matrix or by imposing effect restrictions on the long-run multipliers $C_{i j}(1)$ defined in (2). Once the structural shocks $\varepsilon_{t}$ are identified, the $s$-period-ahead response to shock $\varepsilon_{t}^{i}$ can be computed by

$$
\frac{\partial E\left(Y_{t+s}\right)}{\partial Y_{t}^{i}}=C_{s} \varepsilon_{t}^{i}
$$

where $C_{s}$ is the lag-s matrix derived from the MA representation, $C_{s}=B_{s} * R$ and $\varepsilon_{t}=R^{-1} e_{t} . R$ is a (rotation) matrix that maps the reduced form into the structural form and, thus, depends on the nature of the restrictions imposed.

Since $B(L)$ is generated from the reduced-form estimation, one can easily see that sufficient restrictions on the left-hand side of (A.2.1) can be used to uniquely identify $C(L)$ and $\varepsilon_{t}^{i}$. The alternative identification that we impose in the fourth section of the paper takes a decidedly different tack. Instead of imposing restrictions on either the contemporary impact matrix or the long-run multipliers, we restrict the impulse responses (A.2.1) directly. Since our algorithm imposes only sign restrictions, which may not be binding, we do not exactly identify the structural shock. Instead, we must draw candidate shocks and test whether the sign restrictions are violated. This allows us to identify a distribution of structural shocks, which we use to test the robustness of the conclusions drawn from the estimation in the third section of the paper.

\section{Appendix C}

We begin with the reduced-form, four-lag VAR:

$$
Y_{t}=\sum_{i=1}^{4} D_{i} Y_{t-i}+e_{t}
$$

where the $D_{i}$ are the lag $i$ coefficient matrices, $I-D(L)=A(L)$, and the $e_{i}$ are the i.i.d. reducedform residuals with covariance matrix $\Sigma$. It is convenient to stack the system (A.3.1) in the following manner:

$$
\mathbf{Y}=\mathbf{X D}+\mathbf{e},
$$

where $\mathbf{D}=\left[D_{1}, D_{2}, \ldots D_{k}\right]^{\prime}, \mathbf{Y}=\left[\mathcal{y}_{1}, \mathcal{y}_{2}, \ldots y_{T}\right]^{\prime}$, $X_{t}=\left[y_{t-1}^{\prime}, y_{t-2}^{\prime}, \ldots y_{t-k}^{\prime}\right]^{\prime}, \mathbf{x}=\left[X_{1}, X_{2}, \ldots X_{T}\right]^{\prime}$, and $\mathbf{e}=\left[e_{1}, e_{2}, \ldots e_{T}\right]^{\prime}$. Here, $T$ is the sample length and $k$ is the lag order ( $k=4$ in our case).

The system (A.3.2) can be estimated as a VAR with a normal-inverted Wishart prior conjugate distribution with parameters $v_{0}, N_{0}, \delta_{0}$, and $S_{0}$. Then, the VAR parameters can be drawn from the joint posterior distribution, also a normal-inverted Wishart distribution centered on $\delta$ and $S$ with $v$ degrees of freedom and precision matrix $N$. The parameters for the posterior distribution are given by

$$
\begin{gathered}
v=T+v_{0}, \\
N=N_{0}+\mathbf{X}^{\prime} \mathbf{X} \\
\delta=N^{-1}\left(N_{0} \delta_{0}+\mathbf{X}^{\prime} \mathbf{X} \widehat{D}\right), \\
S=\frac{v_{0}}{v} S_{0}+\frac{T}{v} \hat{\Sigma}+\frac{1}{v}\left(\widehat{D}-\delta_{0}\right)^{\prime} N_{0} N^{-1} \mathbf{X}^{\prime} \mathbf{X}\left(\widehat{D}-\delta_{0}\right),
\end{gathered}
$$

where $\widehat{D}=\left(\mathbf{X}^{\prime} \mathbf{X}\right)^{-1} \mathbf{X}^{\prime} \mathbf{Y}$ and $\hat{\Sigma}=(\mathbf{Y}-\mathbf{X} \widehat{D})^{\prime}(\mathbf{Y}-\mathbf{X} \widehat{D}) \cdot{ }^{24}$

We can characterize the impulse vector $\hat{\theta}$ by

$$
\hat{\theta}=\mathrm{Q} \vartheta,
$$

where $Q Q^{\prime}=\Sigma$ is the Cholesky decomposition of the state-dependent covariance matrix and $\vartheta$ is a vector drawn from the unit circle. The Cholesky factorization does not impose a causal ordering

\footnotetext{
24 In estimating the Bayesian VAR (A.3.2), we utilize uninformative priors. That is, we assume $v_{0}=0$ and $N_{0}=\widetilde{0}_{n}$, with $S_{0}$ and $\delta_{0}$ arbitrary. This makes (A.3.2) a simple reduced-form VAR.
} 
in this case but provides a means of orthogonalizing the shocks. ${ }^{25}$ We then apply (A.3.3) and (A.3.4) to generate impulse responses and test them against the restriction matrix $R$. Any $\hat{\theta}$ that satisfies the restrictions on $y_{t+j}$ is retained. Multiple iterations over a single set of sampled model parameters yield a distribution for the shocks, $\Theta(\mathbf{D}, \Sigma, R) .{ }^{26}$

Suppose the impulse response to any vector innovation $\hat{\theta}$ can be defined as

$$
\Delta y_{t+j}=\Gamma^{j} \bar{\theta}
$$

\footnotetext{
${ }^{25}$ See Mountford and Uhlig (2002) for a discussion of the use of the Cholesky factorization.

26 Our characterization of the impulse vector space is slightly different from Uhlig (1999). He implicitly assumes that the sign restrictions on the impulse response functions hold out to horizon $l$, and he characterizes the space as $\Theta(\mathbf{D}, \Sigma, l)$. Since we will impose long-run restrictions, it is beneficial to denote the impulse vector space as dependent on a restriction matrix $R$.
}

where $\bar{\theta}=\left[\hat{\theta}^{\prime}, 0_{1 \times 2(k-1)}\right]^{\prime}$ and the $(2 k \times 2 k)$ impulsegenerating matrix $\Gamma$ is defined by

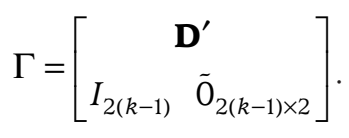

Here, $\mathbf{D}$ is the stacked coefficient matrix, $I_{2(k-1)}$ is the $2(k-1) \times 2(k-1)$ identity matrix and $\widetilde{0}_{2(k-1) \times 2}$ is a $2(k-1) \times 2$ matrix of zeros.

The algorithm for identifying the technology shock is as follows: The impulse response to any shock $\hat{\theta}$ can be calculated using (A.3.3) and (A.3.4). The shock $\hat{\theta}$ is associated with a restriction matrix $R$ that is invariant to the state of the economy. $R$ is an $(n \times l)$ matrix that represents the priors that we impose on the response of model variables to the incidence of a shock $\hat{\theta}$ out to a horizon $l$. Our identification centers on the selection of the shock $\hat{\theta}$ that produces an impulse response satisfying the restriction matrix $R$. 